\title{
A IMPORTÂNCIA DO ENSINO RELIGIOSO NAS ESCOLAS: O PARADOXO EXISTENTE ENTRE O ESTADO LAICO E O ENSINO RELIGIOSO
}

\author{
THE IMPORTANCE OF RELIGIOUS EDUCATION IN SCHOOLS: THE EXISTING PARADOX \\ BETWEEN THE LAIC STATE AND RELIGIOUS EDUCATION
}

\author{
Augusto Rostirolla ${ }^{1}$ \\ José Henrique Gottschalk Pereira ${ }^{2}$ \\ Felipe Rodrigo Kipper ${ }^{3}$ \\ Ivana Georgia Backes ${ }^{4}$ \\ Daniel de Azevedo Crespo 5 \\ Jeronimo Prade da Silva ${ }^{6}$
}

RESUMO: O presente artigo teve por escopo verificar a importância do ensino religioso nas escolas. Para efetuar esta análise, primeiramente, analisou-se o aparente conflito entre o Estado laico e o ensino religioso. Superado este estudo, buscou-se evidenciar a melhor maneira de ministrar tais aulas, focando seu ensino nas diversas religiões, afastando qualquer espécie de doutrinação. Por fim, foi analisada a efetiva importância do ensino religioso nas escolas, visualizando os seus benefícios aos alunos. $O$ objetivo do presente trabalho foi verificar se, de fato, a disciplina de ensino religioso é importante na formação dos alunos, bem como as diretrizes que o professor deve seguir no ministrar das aulas. $O$ procedimento metodológico utilizado foi o bibliográfico.

Palavras-chave: Estado laico, ensino religioso, importância ensino religioso.

ABSTRACT: The purpose of this article was to verify the importance of religious education in schools. To carry out this analysis, firstly, the apparent conflict between the secular state and religious education was analyzed. Having overcome this study, we sought to show the best way to teach such classes, focusing on teaching them in different religions, avoiding any kind of indoctrination. Finally, the effective importance of religious education in schools was analyzed, visualizing its benefits to students. The objective of the present work was to verify if, in fact, the discipline of religious education is important in the education of students, as well as the guidelines that the teacher must follow when teaching classes. The methodological procedure used was the bibliographic.

Keyword: Secular state, religious education, importance of religious education.

\footnotetext{
${ }^{\text {I }}$ Formado em Direito pela Universidade de Santa Cruz do Sul - UNISC/RS.

${ }^{2}$ Formado em Ciências Jurídicas e Sociais pela Pontífice Universidade Católica - PUC/RS.

${ }^{3}$ Formado em Direito pela Universidade de Santa Cruz do Sul - UNISC/RS.

4 Formada em Letras Inglês/Português e Português/Espanhol na Universidade de Santa Cruz do Sul/RS.

5 Formado em Engenharia Mecânica pela Universidade Federal do Rio Grande do Sul - UFRGS/RS.

${ }^{6}$ Formado em Tecnologia em Marketing pela UNINTER.
} 


\section{INTRODUÇÃO}

O presente artigo irá tratar, em um primeiro momento, da relação existente entre o Estado laico e o ensino religioso, analisando as implicações daquele na condução das aulas, bem como a possível quebra do laicismo estatal pelo ensino da matéria, em especial diante do disposto na Constituição Federal de 1988.

Compreendida a relação e as implicações do Estado laico no ensino religioso, verificar-se-á os melhores métodos didáticos para a condução das aulas, bem como os principais temas a serem abordados e o viés a eles conferidos.

Posteriormente, concluída a fase das aulas de ensino religioso, será abordado os reflexos desta para os alunos, elencando os benefícios das mesmas e as possíveis implicações em caso da não observação dos métodos adequados para a condução das aulas.

\section{CONSIDERAÇÕES ACERCA DO ESTADO LAICO E O ENSINO RELIGIOSO}

Neste ponto inicial, estudar-se-á a relação existente entre o Estado laico e o ensino religioso nas escolas, verificando se este viola a laicidade estatal ou não, abordando o tema sob uma ótica constitucional acerca da matéria e o posicionamento de estudiosos do tema.

A Constituição Federal de 1988, em seu artigo $5^{0}$ - o qual elenca o rol exemplificativo de direitos fundamentais individuais e coletivos -, em seu inciso VI a VIII, prevê a liberdade de crença, veja-se:

Art. $5^{\mathrm{O}}$ Todos são iguais perante a lei, sem distinção de qualquer natureza, garantindo-se aos brasileiros e aos estrangeiros residentes no País a inviolabilidade do direito à vida, à liberdade, à igualdade, à segurança e à propriedade, nos termos seguintes:

[...]

VI - é inviolável a liberdade de consciência e de crença, sendo assegurado o livre exercício dos cultos religiosos e garantida, na forma da lei, a proteção aos locais de culto e a suas liturgias;

VII - e assegurada, nos termos da lei, a prestação de assistência religiosa nas entidades civis e militares de internação coletiva;

VIII - ninguém será privado de direitos por motivo de crença religiosa ou de convicção filosófica ou política, salvo se as invocar para eximir-se de obrigação legal a todos imposta e recusar-se a cumprir prestação alternativa, fixada em lei. (BRASIL, I988).

Neste sentido, indiscutível o direito de todos a possuírem e manifestarem a sua crença religiosa, sendo que seu exercício livre e seus locais de culto e suas liturgias devem 
ser protegidos, seja contra ações de particulares ou do Estado. Desta forma, é garantida a liberdade de integrar qualquer seita religiosa, sendo assegurado o direito de mudar de religião, além de compreender, igualmente, a liberdade de não aderir à religião alguma (SILVA, 2009, p. 94).

Estas previsões encontram-se em consonância com os preceitos de igualdade material tão almejados pelo constituinte de 1987 , de modo que, em seu artigo $3^{\circ}$, IV, a constituição veda todo e qualquer tipo de discriminação, acerca do qual Mello (200o, p. 17) expõe:

então, percebe-se, o próprio ditame constitucional que embarga a desequiparação por motivo de raça, sexo, trabalho, credo religioso e convicções políticas, nada mais faz que colocar em evidência certos traços que não podem, por razões preconceituosas mais comuns em certa época ou meio, ser tomados gratuitamente como ratio fundamentadora de discrímen. $\mathrm{O}$ art. 5., caput, ao exemplificar com as hipóteses referidas, apenas pretendeu encarecê-las como insuscetíveis de gerarem, só por só, uma discriminação. Vale dizer: recolheu na realidade social elementos que reputou serem possíveis fontes de desequiparações odiosas e explicitou a impossibilidade de virem a ser destarte utilizados

Por sua vez, a Constituição prevê que o poder público, em todas as suas esferas, não poderá ter uma religião oficial, sendo vedada a concessão de privilégios a qualquer religião ou a sua subvenção, ou seja, há a previsão expressa da laicidade do Estado brasileiro. Assim dispõe o artigo 19, inciso I:

Art. 19. É vedado à União, aos Estados, ao Distrito Federal e aos Municípios:

I - estabelecer cultos religiosos ou igrejas, subvencioná-los, embaraçar-lhes o funcionamento ou manter com eles ou seus representantes relações de dependência ou aliança, ressalvada, na forma da lei, a colaboração de interesse público.

Assim, a simples leitura deste dispositivo permite concluir que o Estado não poderá ter predileção por qualquer culto religioso, não podendo conferir benefícios ou praticar atos que impliquem em embaraços à determinada Religião. Da leitura conjunta dos dispositivos supracitados, verifica-se que o Estado não poderá intervir na prática religiosa das pessoas, bem como não poderá se intrometer nas práticas das diversas religiões existentes, salvo para atuar em parceria dessas a fim de fomentar o interesse público. No mesmo sentido, Soriano 
(2002, p. 85) explica que "o Estado laicista não pode favorecer uma religião em detrimento de outras [...]. Isso não impede, entretanto, que a Igreja e o Estado possam ser parceiros em obras sociais e de interesse público".

Por fim, no capítulo que trata da educação, a Carta Magna brasileira dispõe que o ensino religioso deverá ser disponibilizado pelas escolas públicas, sendo sua matrícula facultativa, consistindo a disciplina nos horários normais, nos termos do artigo 210 § $\mathrm{I}^{\mathrm{O}}$ :

Art. 210. Serão fixados conteúdos mínimos para o ensino fundamental, de maneira a assegurar formação básica comum e respeito aos valores culturais e artísticos, nacionais e regionais.

§ I $\mathrm{O}$ ensino religioso, de matrícula facultativa, constituirá disciplina dos horários normais das escolas públicas de ensino fundamental.

Destarte, verifica-se que, em que pese a Constituição preveja a vedação da adoção de religiões oficiais pelo Estado, este não é contrário a existência das mesmas, muito pelo contrário, o Estado tem o dever de respeitar e proteger todas as liturgias e crenças praticadas. Neste sentido, a fim de convergir com o respeito e proteção às religiões, a própria redação originária da Lei Maior previu a obrigatoriedade da disponibilidade da disciplina de ensino religioso nas escolas públicas, sendo sua matrícula facultativa.

Diante disso, em face da harmonia dos dispositivos da Constituição, verifica-se que o Estado não pode privilegiar nenhuma religião em detrimento das demais, bem como que deve disponibilizar nas escolas públicas o ensino religioso. Assim, a melhor leitura destes dispositivos se dá pelo não privilégio de nenhuma, devendo haver uma exposição isenta de posicionamento acerca das diversas religiões existentes.

\section{MÉTODOS DIDÁTICOS APLICADOS AO ENSINO RELIGIOSO}

Compreendido os apontamentos feitos no ponto anterior, estudar-se-á os melhores métodos didáticos a serem aplicados nas aulas de ensino religioso, tendo em vista que o Estado não poderá adotar uma religião, nem poderá conceder privilégios a qualquer doutrina. Neste sentido, importante que se tenha um profissional qualificado para ministrar as aulas, a fim de evitar que ocorram discrepâncias e catequizações em plena sala de aula.

O Estado brasileiro confere uma inegável importância ao ensino religioso, sendo que este deverá sempre ser disponível na rede pública de ensino. Todavia, não é possível que 
esta aula se torne em catequização de uma religião específica. Assim, o professor deverá dominar um conhecimento acerca das diversas religiões existentes, sendo capaz de expor suas peculiaridades e de transmitir uma visão desprovida de qualquer preconceito, abrindo sempre espaço para um debate crítico, criando um meio de diálogo construtivo com os alunos. Nesse sentido,

somente quem escuta paciente e criticamente o outro, fala com ele, mesmo que, em certas condições, precise falar a ele. O que jamais faz quem aprende a escutar para poder falar com é falar impositivamente [...] O educador que escuta aprende a difícil lição de transformar o seu discurso, às vezes necessário, ao aluno, em uma fala com ele (FREIRE, 2002, p I27-I28).

Para que seja possível um diálogo construtivo entre professor e aluno, é indispensável que o profissional contemple a importância de conhecer a diversidade religiosa, possua um conhecimento atual acerca da religião em diferentes culturas e tradições, estimule um diálogo com o diferente, debatendo a percepção do religioso presente nas relações humanas e nos meios de comunicação social. Assim, a presença destes elementos é indispensável para a inter-relação nas salas de aula, sendo, deste modo, possível a promoção do respeito à diversidade, agregando ao aluno uma nova compreensão do que é importante para o outro e os seus porquês (OLENIKI, 2003, p. 16-I7).

O fito do ensino religioso está em auxiliar os infantes à descoberta de si e do outro, visando a construção de uma sociedade mais justa e solidária, na qual uns entendam as necessidades dos outros. Desta forma, quando o conteúdo é devidamente trabalho com as crianças, utilizando métodos de fácil compreensão, contextualizando a realidade com os valores religiosos, o ensino religioso torna-se um meio eficaz para o entendimento e respeito às diferenças (SANTOS, 2009, p. 66).

Ao lado da exposição acerca das diversas religiões existentes, é fundamental que o professor trate acerca da ética, moral e valores. Estes temas, no contexto contemporâneo, são fundamentais para a formação de um cidadão crítico e integrante da sociedade moderna, sempre conduzindo as discussões para o aperfeiçoamento dos valores inerentes à pessoa. Deste modo, a ética e a moral, são indispensáveis ao convívio em sociedade, visto que

constantemente no nosso cotidiano encontramos situações que nos colocam problemas morais. São problemas práticos e concretos da nossa vida em sociedade, ou seja, problemas que dizem respeito às nossas decisões, escolhas, ações e comportamentos - os quais exigem uma avaliação, um 
julgamento, um juízo de valor entre o que socialmente é considerado bom ou mau, justo ou injusto, certo ou errado, pela moral vigente ${ }^{7}$ (MORAIS, 2014).

Deste modo, o ensino da ética e da moral, bem como suas nuances e relevâncias para o cotidiano do cidadão, são indispensáveis para a formação de pessoas atuantes e despidas de preconceitos. Assim, o conhecimento das diversas prática religiosas, bem como sua história, é fundamental para que a aula de ensino religioso seja devidamente ministrada, sendo necessária uma eficaz análise dos professores encarregados do ensino, combatendo veementemente toda a doutrinação religiosa e catequização.

Portanto, o que se verifica é que a melhor técnica de ensino se pauta no estudo da diversidade religiosa, as quais devem ser estudadas sob uma análise pela ética e moral, buscando a construção de valores indispensáveis aos cidadãos que integrarão a sociedade contemporânea. Para isso, é essencial que o professor que ministrará a disciplina seja capacitado e não apresente um comportamento voltado à doutrinação religiosa.

Finalizada essa abordagem acerca dos corretos métodos para ministrar a disciplina de ensino religioso, passar-se-á ao estudo da importância dessa matéria, verificando os benefícios trazidos aos alunos.

\section{ANÁLISE ACERCA DA IMPORTÂNCIA DO ENSINO RELIGIOSO NAS ESCOLAS}

No presente ponto será realizada uma análise acerca da relevância do ensino religioso nas escolas, verificando se este traz benefícios aos alunos e a sua importância na formação dos estudantes como cidadãos. Neste sentido, a análise se dará em conformidade com o estudado anteriormente, sempre levando em consideração o respeito às diversidades religiosas e à primazia do ensino da ética e da moral.

Primeiramente, cumpre repisar que a didática aplicada nas aulas ensino religioso deve estar em consonância com a laicidade estatal e deve se pautar na pluralidade religiosa e nos valores, conforme já exposto. Assim, caso estes não sejam devidamente observados, as

\footnotetext{
7 A autora complementa dizendo que a Ética exige uma atitude crítica do ser humano sobre a moral, o que permite questionar as práticas, leis, convenções, impedindo que a moral se torne um dogma, ou seja, uma verdade fechada em si mesma. Tal questionamento pressupõe um conflito entre o interesse particular e o coletivo. É por isso que precisamos conversar sobre este tema, de fundamental importância para a garantia dos direitos humanos (MORAIS, 2014)
} 
aulas de ensino religioso não trarão os benefícios almejados, podendo acarretar em prejuízos aos alunos, inclusive, fomentando a intolerância religiosa e o preconceito.

Destarte, o ensino religioso possui um fito fundamental de explicar ao aluno e fazer com que esse reflita acerca de temas não abordados pelas ciências exatas. Nesse sentido, a atual leitura ao ensino religioso deve se dar no sentido de uma formação pessoa, o que nem sempre ocorreu na história brasileira. Deste modo

no decorrer da história educacional do Brasil, houve várias tendências sobre a forma de conhecer o Transcendente. Das três concepções de Ensino Religioso que existem no Brasil, no que se refere ao termo "religião", a mais recente situa-se na visão de uma "releitura" (do latim: "relegere", significa: reler) a respeito do fenômeno religioso, que se caracteriza pelo conhecimento hermenêutico, a partir do convívio social, no saber de si, e não como catequese ("reelegere", quer dizer: reescolher), como um povo escolhido, embora haja uma aceitação muito forte e atuante sobre as questões éticas ou vivência de valores ("religere", isto é, religar a pessoa à Deus) (SERAFIM, 2009)

Percebe-se, então, que o ensino religioso pauta-se, essencialmente, na transmissão valores importantes para a sociedade e na consolidação do caráter aos alunos. Diante disso, além do conhecimento acerca das características das diversas religiões existentes, os alunos encontram, com o auxílio desta disciplina, respostas para diversas perguntas referente à cultura, vida, sociedade, família, comportamento entre outros. Assim,

a religião, seja ela qual for, irá trazer princípios éticos e filosóficos básicos, onde a criança, futuramente, poderá decidir se seguirá ou não. Até lá ela terá em mente bons princípios, tais como o bom relacionamento com o próximo, o verdadeiro valor da família, e de como ela já é e sempre será importante para a sociedade (COLUNA PORTAL EDUCAÇÃO, 2013).

Conforme se verificou, o ensino religioso contemporâneo está intimamente ligado à formação moral e ética dos alunos, apresentando-lhes as diversas religiões e transmitindo os mais caros valores da sociedade, a fim de auxiliar na formação de cidadãos atuantes na sociedade. Assim, longe do outrora vigente método de ensino, baseado na doutrinação e na catequização, a matéria de ensino religioso preocupa-se, primordialmente, com a formação de valores positivos e na consolidação do caráter dos estudantes.

Portanto, na medida em que o aluno conhece as diversas práticas religiosas, sob um olhar pautado pela ética e pela moral, é possível a construção de cidadãos bem preparados 
para o ingresso na sociedade contemporânea, permeados pelos mais caros valores de solidariedade e desprovidos de preconceitos.

Nesse sentido, o ensino religioso se denota em efetivo mecanismo de tolerância, auxiliando a criação de uma sociedade mais justa e inclusiva, na qual os interesses e limitações de cada pessoa são respeitados. Ainda, serve como meio para a criação de sociedade sem preconceitos, com cidadãos atuantes no alcance do bem comum.

\section{CONCLUSÃO}

Com o presente trabalho, perquiriu-se acerca das relações da proteção conferida à religiosidade e o laicismo estatal, compreendendo que a presença dessas aulas nas escolas, de matrícula facultativa, encontra-se em consonância com o disposto na Constituição Federal. Diante disso, não há que se falar em afronta a separação entre Estado e religião pelo fato de as escolas disponibilizarem aulas de ensino religioso.

Em contraponto, analisou-se os métodos adequados para a condução destas aulas, verificando que estas não podem se tornar em catequização e doutrinação de determinada religião. Pelo contrário, conforme compreendido, as aulas devem se pautar na pluralidade religiosa, fazendo uma abordagem das diversas religiões existentes, bem como no ensino acerca da ética e da moral.

Superado os métodos aplicados na condução das aulas, estudou-se as implicações que este ensino produz na vida e aprendizagem dos alunos, de modo que, quando corretamente ministrada, a disciplina é de grande valia para a formação de valores importantes para a sociedade e na consolidação de cidadãos de caráter íntegro.

Dessa forma, é possível confirmar que o ensino religioso não ofende na laicidade estatal, muito pelo contrário, ao tratar de todas as religiões, inclusive da ausência dessas (ateísmo), este fomenta a consolidação de uma sociedade mais justa e solidária, na qual os cidadãos, ao conhecerem as realidades dos outros, se tornam sensíveis a estes, rompendo com um círculo de preconceito enraizado na atual sociedade. 


\section{REFERÊNCIAS}

BRASIL. Constituição Federal (1988). Constituição da República Federativa do Brasil. Brasília, DF: Senado Federal, 1988.

COLUNA PORTAL EDUCAÇÃO. A importância do ensino religioso já na infância. 2013. Disponível em: < https://www.portaleducacao.com.br/conteudo/artigos/ educacao/aimportancia-do-ensino-religioso-ja-na-infanci/51258>. Acesso em: II jun. 2017.

MELlO, Celso Antônio Bandeira de. Conteúdo jurídico do princípio da igualdade. 3. ed. São Paulo: Malheiros, 2000.

MORAIS, Maria Aparecida Dantas. A importância do ensino religioso para formação dos valores do aluno. 2014. Disponível em: 〈http://www.webartigos.com/artigos/a-importancia-doensino-religioso-para-formacao-dos-valores-do-aluno/r28198/ \#ixzz4jozCOQLd>. Acesso em: 08 jun. 2017.

OLENIKI, M. L.; DALDEGAN V. M. Encantar: uma prática pedagógica no ensino religioso. Rio de Janeiro: Vozes, 2003.

SILVA, José Afonso da. Comentário contextual à Constituição. 6. ed. São Paulo: Malheiros, 2009.

Santos, Silvana Fortaleza dos. Ensino religioso: uma perspectiva para a educação infantil e os anos iniciais do ensino fundamental. Paraná: Ibepex, 2009.

SERAFIM, Jonas. A importância do ensino religioso na escola. 2009. Disponível em: < http://ensinoreligioso-serafimjonas.blogspot.com.br/2009/o8/diante-de-tantasespeculacoes-respeito.html〉. Acesso em: 09 jun. 2017.

SORIANO, Aldir Guedes. Liberdade religiosa no direito constitucional e internacional. São Paulo: Juarez de Oliveira, 2002. 